\title{
Characterizing potential risk triggered by road traffic noise in comparison with typical air pollutants $\mathrm{NO}_{2}$ and $\mathrm{PM}_{2.5}$
}

\author{
Yuki Okazaki ${ }^{1}$ Lisa Ito ${ }^{1} \cdot$ Akihiro Tokai $^{1}$ (D
}

Accepted: 27 January 2021 / Published online: 11 February 2021

(c) The Author(s), under exclusive licence to Springer Science+Business Media, LLC part of Springer Nature 2021

\begin{abstract}
Characterizing multiple risk stemming from automobiles are required from the viewpoint of priority setting for future risk management. However, little is known about such issues given the inadequacy of indicators. In this research, with the illustration of the metropolitan city of Osaka, Japan, using disability-adjusted life years (DALYs), impacts of road traffic noise and exhausts gas (nitrogen dioxide $\left(\mathrm{NO}_{2}\right)$ and particulate matter $\left(\mathrm{PM}_{2.5}\right)$ ) were quantified and compared with the risks of ischemic heart disease and high sleep disturbance; and respiratory disease as endpoints, respectively. Health risks due to automobile noise were 3102.1 and 97.8 DALYs under the condition of open and closed windows, respectively. The health risks were reduced by $96.8 \%$ under closed-window condition. On the other hand, the health risks caused by $\mathrm{NO}_{2}$ and $\mathrm{PM}_{2.5}$ from automobiles were 137.6 DALYs, which was lower than the health risks due to automobile noise. These results indicate the effectiveness of DALYs as an indicator to characterize different kinds of burden of health and environmental impacts from automobiles, and they were successfully used to evaluate the effectiveness of risk reduction options such as the difference between open and closed windows. Furthermore, most people were found to have been exposed to 55-60 dB noise level. Although they easily get used to and can tolerate this level, it is also the stage at which health risks begin to occur. Therefore, with continuous exposure, qualitative estimation showed that open windows under this noise level subsequently leads to high potential health risks.
\end{abstract}

Keywords Road traffic noise $\cdot \mathrm{NO}_{2} \cdot \mathrm{PM}_{2.5} \cdot$ Health risks $\cdot$ Disability-adjusted life years

\section{Introduction}

The number of automobiles in Japan has spread rapidly along with the post-war economic growth, considering that the country's number of automobiles had increased from approximately 8 million in 1966 to an estimated 30 million in 1976 (AIRIA 2020). The current number of automobiles is nearly 80 million (AIRIA 2020), which is equivalent to two-thirds of the population of Japan with an estimated 120 million people. Furthermore, the number of automobiles to land area is 207 automobiles $/ \mathrm{km}^{2}$ in Japan and much higher than that in the United States, which has the largest number of automobiles in the world ( 29 automobiles $/ \mathrm{km}^{2}$ ), and China, which has the largest population (24 automobiles/ $\mathrm{km}^{2}$ ) (AIRIA 2020). This scenario indicates that Japan is one

Akihiro Tokai

tokai@see.eng.osaka-u.ac.jp

1 Osaka University, 2-1 Yamadaoka, Suita, Osaka 565-0871, Japan of the world's leading automotive nations, and automobile is regarded an essential transportation for the daily life and economic activities of the citizens. Nonetheless, automobiles have caused problems such as air pollution, carbon dioxide emission, and unhampered noise and vibration (van Gent and Rietveld 1993; Fenger 1999; Xu and Lin 2015). The Ministry of Internal Affairs and Communications in Japan has summarized complaints to the "National Pollution Complaints Center." The most frequent complaint received in fiscal year (FY) 2018 was related to noise, accounting for $32.9 \%$ (15,665 cases) of the total number of complaints (MIC 2019). Noise is a familiar problem in our lives, and it remains to be a problem that cannot be ignored.

In Japan, the regulation against road traffic noise was discussed for the first time in the "National Diet of Pollution" in 1970. The environmental quality standards at that time were based on the principle that noise should not cause sleep disturbance, conversation disturbance, reduced work efficiency, or discomfort in daily life (INCE/J 2019). Babisch (2008) found that noise stimulates the autonomic nervous 
system and endocrine system, resulting in ischemic heart disease, further contributing to the understanding of the exposure-response relationship in several epidemiological studies. Miedema et al. (2003) determined the relationship between road traffic noise and sleep disturbance based on the results of "self-reported sleep disturbance." WHO/Europe (2011) estimated the burden of certain diseases, such as cardiovascular disease, cognitive impairment in children, sleep disturbance, tinnitus, and annoyance, as a result of road traffic noise in EU countries. Their results showed that at least one million disability-adjusted life years (DALYs) are lost per year (WHO/Europe 2011).

Although the quality of life (QOL), years of life lost (YLL), years lost due to disability (YLD), and DALYs have been used in Japan, the first one does not assess mortality and morbidity, and the second and third ones only assess mortality or morbidity, respectively (MHLW 2000). However, DALYs are able to account for both the YLL and YLD, and are widely used in the fields of environmental epidemiology and public health. It also enables us to quantify and compare different types of health endpoints, which consider both mortality and morbidity by simplifying the loss of health status based on the concept of the physical labor productivity, age-weighting, and disability-weighting (GBD 2017 DALYs and HALE Collaborators 2018). Although quantification processes to calculate DALYs have been pointed out from the viewpoints of ethical and medical aspects (Sayers and Fliedner 1997), for its quantification capability, it is widely used in the decision-making process on health and environmental regulation such as prior evaluation of Registration, Evaluation, Authorization and Restriction of CHemical (REACH) in the European Union (WWF 2003).

The addition of the health effects of ischemic heart disease and high sleep disturbance and the quantification of these risks with DALYs are also useful in the conception of future policies regarding automobiles in Japan, because the health effects of road traffic noise have been regarded the only sensory pollution in Japan.

Tagusari et al. (2017) developed a noise map for Sapporo City and estimated the exposed population and health effects based on the map. Their result showed that an estimated 20 people had died annually due to ischemic heart disease caused by road traffic noise at daytime (Tagusari et al. 2017). This number was reported to be higher than the number of deaths from tuberculosis (14 deaths) and influenza (6 deaths) (Tagusari et al. 2017). In addition, approximately $2 \%$ of the population $(44,186$ people individuals) of Sapporo City had been affected by high sleep disturbance caused by road traffic noise at night-time (Tagusari et al. 2017). In this study, the number of deaths and mortality rates were compared with the other causes of death. Although the risks of patients with ischemic heart disease who did not die and the population affected by high sleep disturbance with other diseases could not be easily compared, an assessment of the health risks by using DALYs could help to overcome the challenge.

Tobias et al. (2015) estimated the number of annual deaths that could be avoided by reducing road traffic noise for people over 65 years old in Madrid. They found that road traffic noise was associated with cardiovascular and respiratory diseases, and $1 \mathrm{~dB}$ reduction in daytime road traffic noise was equivalent to 284 reductions in annual deaths from cardiovascular diseases and 184 reductions in annual deaths from respiratory diseases (Tobias et al. 2015). The study also showed the change in deaths with $10 \mu \mathrm{g} / \mathrm{m}^{3}$ reduction in particulate matter $\left(\mathrm{PM}_{2.5}\right)$, which can be compared with the risk of road traffic noise, and concluded that exposure to traffic noise should be considered an important environmental factor because of its significant impact on health, (Tobias et al. 2015). WHO/Europe (2011) estimates that the DALYs for sleep disturbance were the highest among EU countries; therefore, the effect of sleep disturbance due to road traffic noise should be integrated into the estimation of traffic noise impacts.

Eriksson et al. (2017) assessed the burden of disease from automobile and railroad noise using DALYs for the whole of Sweden. The endpoints were annoyance, sleep disturbance, hypertension, and myocardial infarction, and the approach of WHO/Europe (2011) was used to calculate the DALYs. An estimated 41,033 DALYs were lost from the transport sector, in which 36,711 DALYs were due to road traffic noise (Eriksson et al. 2017). However, considering that the population in Sweden is approximately 10 million, which is nearly one-twelfth of the population of Japan, and its land area is large and the population density is low compared with those of Japan, we assume that the derived results regarding the effects in Sweden are somewhat limited in Japan's context.

With the aforementioned backgrounds, a risk assessment that sets ischemic heart disease and high sleep disturbance in Japan as the endpoint of health risk should be implemented. The objectives of this study are (i) to clarify the health risks due to road traffic noise in Osaka City, which was reported as having the highest traffic volume and population density in Japan, and (ii) to compare the health risks due to road traffic noise with those due to air pollutants from automobiles in the same area using the common indicator, DALYs. This study can promote the recognition of the significant health effects of road traffic noise and the discussion of transportation policies that consider health risks. 


\section{Selection of locations for evaluation}

A densely populated location is considered to be highly sensitive to the impact of road traffic noise due to the density of roads, residences, and workplaces. Traffic volume is one of the factors that can help to determine the level of road traffic noise (Sakamoto 2014). Therefore, we decided to select locations with high traffic volume and population density as the target locations of this study. Osaka Prefecture, which is the center of the economy, culture, and transportation in western Japan, was reported as having the highest transport ton-kilometers $(12,782,090$ thousand ton-kilometers) in FY 2018 among the six major prefectures (Tokyo, Kanagawa, Aichi, Osaka, Hyogo, and Fukuoka prefectures) (MLIT 2019a) and the second highest transport person-kilometers $(5,412,465$ thousand person-kilometers) in FY 2018 following the 10,618,884 thousand person-kilometers of Tokyo, the capital of Japan (MLIT 2019b). The population and density of Osaka City is estimated to be 2.7 million people and 11,949 person $/ \mathrm{km}^{2}$, respectively, which are the highest among the ordinance-designated cities (Statistics Bureau of Japan 2016). On the basis of the aforementioned considerations, we can deduce that Osaka City is the most appropriate location for this study (Fig. 1). Furthermore, National Road 43, which is known as the place where the Supreme Court of Japan ruled for the first time in 1995 on road traffic noise (Supreme Court of Japan 1995a, b), is also a significant reason for the target location selection. A stretch of National Road 43 runs through Osaka City.
In this study, we mainly used data from several actual observations. The time period when the data coincide with one another was desirable for this research. The year 2010, the most recent year in which the study conditions could be generally met and data were available, was selected as the target period. The target area was the roadside of Osaka City where the Road Traffic Census was conducted; the Road Traffic Census is a survey of road traffic conducted regularly by the Ministry of Land, Infrastructure, Transport and Tourism in Japan and contains automobile type, travel speed, running condition, and traffic volume data, which are necessary in noise level estimation (JSTE 2012). The Ministry of Environment in Japan defines the area within $50 \mathrm{~m}$ of the road edge as "the area where noise from automobile is the dominant source of noise" (MOE 2015a). Therefore, in this study, the area within $50 \mathrm{~m}$ of the road edge was selected as the target for the evaluation (Fig. 2). However, the National Expressways and Urban Expressways were excluded from the study because most of their road stretches are parallel to the General National Highway and General Prefectural Highway, and estimating the exposed population is difficult. In addition, Fukazawa et al. (2016) reported that individual building height and building use are unnecessary information when estimating the population with health effects from the distribution of population exposed to vehicle noise. Therefore, this study assumed the presence of one-story buildings in the evaluation area that are within $50 \mathrm{~m}$ of the road edge.

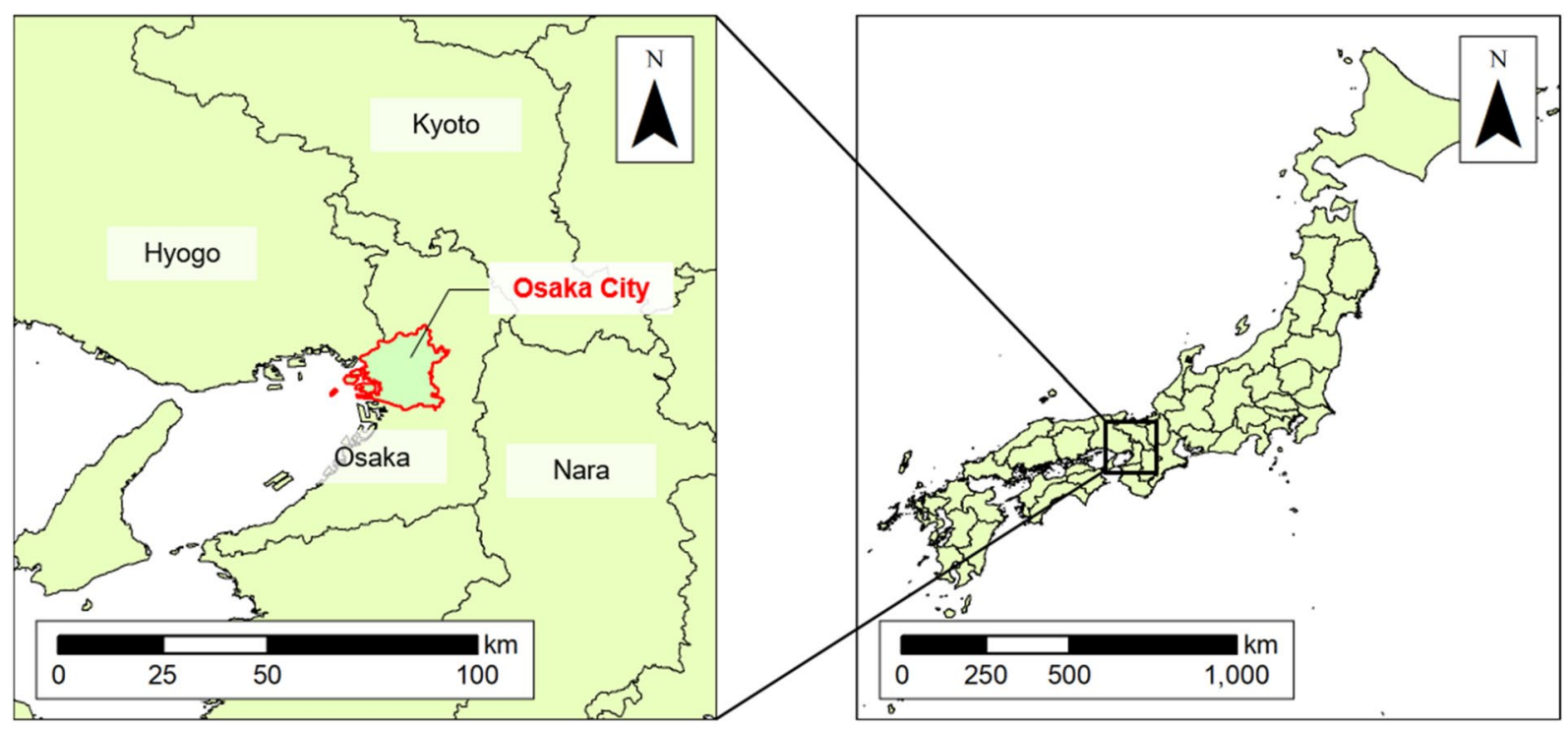

Fig. 1 Location of Osaka City. Osaka City is the center of Osaka Prefecture, which consists of 24 wards and is located in Western Japan and includes numerous schools, offices, and factories 
Fig. 2 Evaluation target. The gray and dotted areas represent the road and roadsides, respectively. We estimated the exposed population assuming that the population in the dotted evaluation area is evenly distributed with the population density of the ward in which the road is located

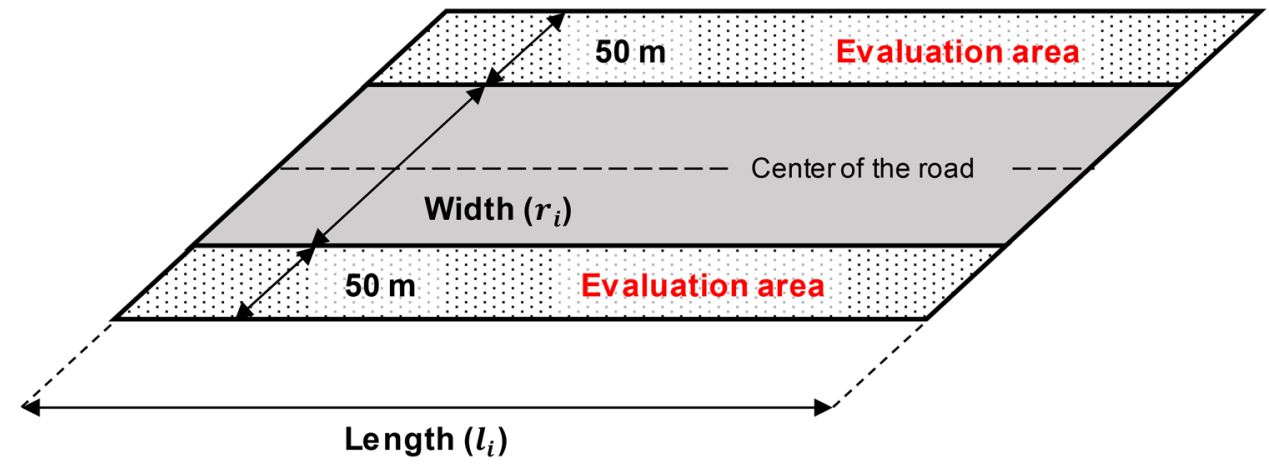

\section{Methodology}

\subsection{Prediction of road traffic noise}

\subsubsection{Estimation of A-weighted equivalent sound pressure level}

The health effects at the receiving point in this study were estimated by predicting the level of road traffic noise at the source. The A-weighted equivalent sound pressure level is one of the indices used to express the average noise level of time-varying noise, such as road traffic noise, in line with the environmental quality standards in Japan. The sound power level is that of energy emitted by one automobile from a point source, whereas the A-weighted sound power level is the variable corrected for human health risk estimation, as human hearing varies with frequency (e.g. low-frequency sounds are hard to hear). Therefore, the A-weighted equivalent sound pressure level at the analysis site was estimated initially prior conducting the health risk assessment derived from noise. The ASJ RTN-Model 2013 (Sakamoto 2014), which is a prediction model for road traffic noise, was used to estimate the A-weighted equivalent sound pressure level. Figure 3 shows the process of estimating the A-weighted equivalent sound pressure level. For the prediction of road traffic noise, the Road Traffic Census (JSTE 2012) was used to provide information on automobile type, travel speed, running condition, and traffic volume, in which a "traffic survey base section number" could be assigned to each road section. In this study, the A-weighted equivalent sound pressure level was estimated for each road section with a "traffic survey base section number." The method for determining

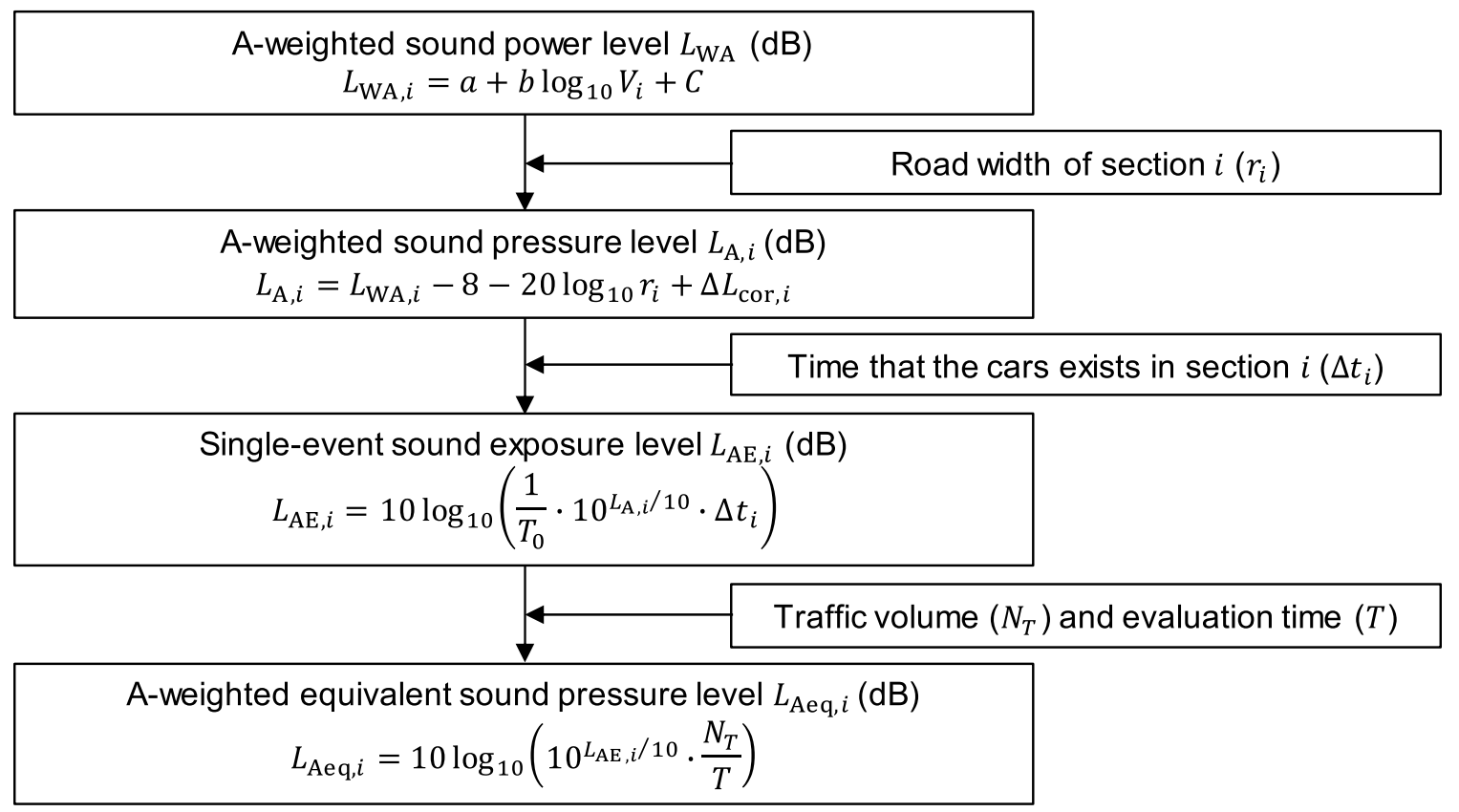

Fig. 3 Flowchart of road traffic noise prediction 
the A-weighted equivalent sound pressure level in section $i$ is presented in the succeeding discussions.

First, the A-weighted sound power level $L_{W A, i}$ (Eq. 1) (Sakamoto 2014) was calculated from the travel speed $V_{i}$, which is the value obtained by dividing the distance of a certain section by the time needed to pass through. Considering that the traffic conditions in Osaka City differ between daytime (6:00-22:00) and night-time (22:00-6:00) and the nighttime data needed for this research were lacking, the "daytime 12-h average travel speed" and the "daytime non-congested average travel speed" (JSTE 2012) were set as the daytime travel speed and night-time travel speed, respectively. The constants $a$ given for each automobile type and the coefficients $b$ give for each travel speed (Sakamoto 2014) are shown in Table 1. The constants $a$ differ between small-sized automobiles (passenger cars/small freight vehicles) and large-sized automobiles (medium/large vehicles). The coefficients $b$ differ between "steady-state sections" (automobiles travel in close proximity to top gear) and "non-steady-state sections" (automobiles frequently accelerate and decelerate). The "steadystate section" is defined as the section with average travel speed of more than $40 \mathrm{~km} / \mathrm{h}$, whereas the "non-steady-state section" is defined as the section with average travel speed of less than $40 \mathrm{~km} / \mathrm{h}$. The correction term $C$ includes road pavement, slope, and noise directivity (Sakamoto 2014).

$L_{W A, i}=a+b \log _{10} V_{i}+C$

where

$\mathrm{L}_{\mathrm{WA}, i}:$ A-weighted sound power level in section $i(\mathrm{~dB})$.

$a$ : Constants given for each automobile type (-).

$b$ : Coefficients given for each travel speed (-).

$V_{i}$ : Travel speed in section $i(\mathrm{~km} / \mathrm{h})$.

$C$ : Correction term $(\mathrm{dB})$.

Then, the A-weighted sound pressure level $L_{\mathrm{A}, i}$ (Eq. 2) (Sakamoto 2014) was calculated from the A-weighted sound power level obtained from Eq. 1, which can describe the noise level observed at the predicted point away from the noise source when one automobile is driving. In this study, the distance from the source to the predicted point was set to $r_{i} / 2$ by using road width $r_{i}$ for section $i$ (Fig. 2) because

Table 1 Values of constant $a$ and coefficient $b$ at each of steady-state or non-steady-state section

\begin{tabular}{llllll}
\hline & \multicolumn{2}{l}{ Steady-state section } & \multicolumn{2}{l}{$\begin{array}{l}\text { Non-steady- } \\
\text { state section }\end{array}$} \\
\cline { 2 - 3 } \cline { 5 - 6 } \cline { 5 - 6 } & $\mathrm{a}$ & $\mathrm{b}$ & & $\mathrm{a}$ & $\mathrm{b}$ \\
\hline Small-sized automobiles & 46.7 & 30 & & 82.3 & 10 \\
Large-sized automobiles & 53.2 & & & 88.8 & \\
\hline
\end{tabular}

the source is assumed to exist in the middle of the road. The correction term $\Delta L_{c o r, i}$ includes attenuation associated with diffraction, attenuation related to ground surface effects, and attenuation due to acoustic absorption of air (Sakamoto 2014).

$L_{A, i}=L_{W A . i}-8-20 \log _{10}\left(r_{i} / 2\right)+\Delta L_{c o r, i}$

where.

$L_{\mathrm{A}, i}:$ A-weighted sound pressure level in section $i(\mathrm{~dB})$.

$r_{i}$ : Distance from the source to the predicted point in section $i(\mathrm{~m})$.

$\Delta L_{c o r, i}:$ Correction term $(\mathrm{dB})$.

Subsequently, the single-event sound exposure level $L_{A E, i}$ (Eq. 3) (Sakamoto 2014) was calculated from the A-weighted sound pressure level obtained from Eq. 2. The single-event sound exposure level represents the value obtained by converting the single-event noise, such as noise that lasts for $1 \mathrm{~s}$, was converted into a level of steady-state noise. $\Delta t_{i}$ represents the time when the noise source was present on the road in section $i$ and was substituted by dividing the length of the road in section $i$ by the average travel speed.

$L_{A E, i}=10 \log _{10}\left(\frac{1}{T_{0}} \cdot 10^{L_{A, i} / 10} \cdot \Delta t_{i}\right)$

where.

$L_{A E, i}:$ Single-event sound exposure level in section $i(\mathrm{~dB})$.

$T_{0}$ : Unit time (s).

$\Delta t_{i}$ : The time when the noise source is present in section $i$ (s).

The A-weighted equivalent sound pressure level $L_{\text {Aeq,i }}$ (Eq. 4) (Sakamoto 2014) was calculated from the singleevent sound exposure level obtained from Eq. 3. The A-weighted equivalent sound pressure level indicates the average noise level for time-varying noise, such as road traffic noise, at a fixed time (daytime and night-time). $T$ is the predicted time, with 57,600 s for daytime (6:00-22:00) and 28,800 s for night-time (22:00-6:00). $N_{T}$ represents the traffic volume during the predicted time. The traffic volume at daytime is calculated by multiplying "daytime 12-h (7:00-19:00) traffic volume" of the Road Traffic Census (JSTE 2012) by 16/12, whereas the traffic volume at night-time is calculated by multiplying the value obtained by subtracting "daytime 12-h traffic volume" from the " $24-\mathrm{h}$ traffic volume" by $8 / 12$.

$L_{\text {Aeq }, i}=10 \log _{10}\left(10^{L_{A E, i} / 10} \cdot \frac{N_{T}}{T}\right)$

where.

$L_{\text {Aeq, },}:$ A-weighted equivalent sound pressure level in section $i(\mathrm{~dB})$.

$T$ : Predicted time (s). 
$N_{T}$ : Traffic volume during the predicted time $T$ (automobiles).

In Eqs. 1-4, the A-weighted equivalent sound pressure level is estimated for each automobile type. In Eq. 5, these A-weighted equivalent sound pressure levels are integrated. Here, $L_{\text {Aeq }, i}^{\text {small }}$ and $L_{\text {Aeq }, i}^{\text {large }}$ are the A-weighted equivalent sound pressure levels for the small-sized and large-sized automobiles, respectively.

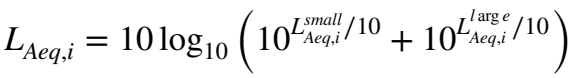

where.

$L_{\text {Aeq, } i}^{\text {small: }}$ A-weighted equivalent sound pressure level from small-sized automobiles $(\mathrm{dB})$.

$L_{\text {Aeq, } i}^{\text {large }}$ A-weighted equivalent sound pressure level from large-sized automobiles $(\mathrm{dB})$.

In Osaka City, road traffic noise is measured every year to grasp the achievement status of the environmental quality standards. The National Institute for Environmental Studies (2020) summarizes the location, date and time of measurement, observed values, etc., and the information is available for download. We compared the measured values and estimated values in Eq. 5 and subsequently calibrated the data based on the least-square method.

Finally, the health risk in the indoor environment is estimated by taking into account the sound performance of buildings. The sound performance of buildings is not necessarily uniform across buildings, but the average difference of noise levels in a normal building with opened windows can be set to $10 \mathrm{~dB}$, whereas those with closed windows is $25 \mathrm{~dB}$ (MOE 2015b). Thus, in this study, 10 and $25 \mathrm{~dB}$ were subtracted from the calibrated values for each case considered in the evaluation.

\subsubsection{Estimation of exposed population}

People with constant population density $D_{i}$ (Statistics Bureau of Japan 2014) in each section of the road is assumed in this study. We have also assumed that the length of the road in section $i$ is $l_{i}$, and the exposed population $P_{i}$ in section $i$ is given by Eq. 6 . The range of the evaluation area is $50 \mathrm{~m}$ from the edge of the road, but we doubled the range because of the presence of people on both sides of the road.

$P_{i}=2 \cdot\left(50 \cdot \frac{1}{1000} \cdot l_{i} \cdot D_{i}\right)$

where

$P_{i}$ : Exposed population in section $i$ (person).

$l_{i}$ : Length of the road in section $i(\mathrm{~km})$.

$D_{i}$ : Population density in the ward where section $i$ is located (person $/ \mathrm{km}^{2}$ ).
The daytime population in Osaka City is larger than the night-time population, and this difference can be attributed to the locations of many offices and schools in the city. In this study, the exposed population at daytime (6:00-22:00) was calculated by multiplying the exposed population at night-time (22:00-6:00) by the ratio of daytime population per ward (24 wards) (Statistics Bureau of Japan 2014).

\subsection{Estimation of health risks due to road traffic noise}

\subsubsection{Effects on ischemic heart disease}

The autonomic nervous and endocrine systems stimulated by noise affect blood pressure, heart rate, and cardiac output, leading to cardiovascular disease (Babisch 2011). Although it includes ischemic heart disease, hypertension, and strokes, Babisch (2008) showed a strong association between ischemic heart disease and noise. The odds ratio for ischemic heart disease and the exposure-response relationship for the A-weighted equivalent sound pressure level (Eq. 7) were obtained from two descriptive studies and five analytical studies (Babisch 2008). WHO/Europe (2011) has adopted it to estimate the health effects of noise quantitatively, and this method has also been applied to Japan (Tagusari et al. 2017) and thus was also used in this study. We decided to estimate the health risk at noise levels higher than $55 \mathrm{~dB}$ because this equation has been applied by Babisch (2008) via the 55-80 dB range and MOE (2012) for the environmental standard set as $55 \mathrm{~dB}$ at daytime for residential areas in Japan.

$O R=1.629657-0.000613 \cdot\left(L_{d a y, 16 h}\right)^{2}+0.000007357 \cdot\left(L_{d a y, 16 h}\right)^{3}$

where

OR: Odds ratio (-).

$L_{d a y, 16 h}$ : Daytime (16 h) A-weighted equivalent sound pressure level (dB).

The process of estimating the health risk of ischemic heart disease due to road traffic noise DALY IHD,automobiles $_{\text {is }}$ shown in Fig. 4. The health risk of ischemic heart disease due to road traffic noise is calculated as the product of the health risk of ischemic heart disease DALY ${ }_{\mathrm{IHD}}$ and "population attributable fraction (PAF)" (Eq. 8) (WHO/Europe 2011). DALY ${ }_{I H D}$ is the sum of $Y L L_{I H D}$ and $Y L D_{I H D}$ (Eq. 9) (Murray and Lopez 1996). PAF is the proportion of deaths and patients of ischemic heart disease attributable to noise, which is calculated by Eq. 10 (WHO/Europe 2011). $P_{k}$ is the ratio of the exposed population in noise level band $k$ to the total exposed population. The value calculated by Eq. 7 is used for $O R_{k}$. 


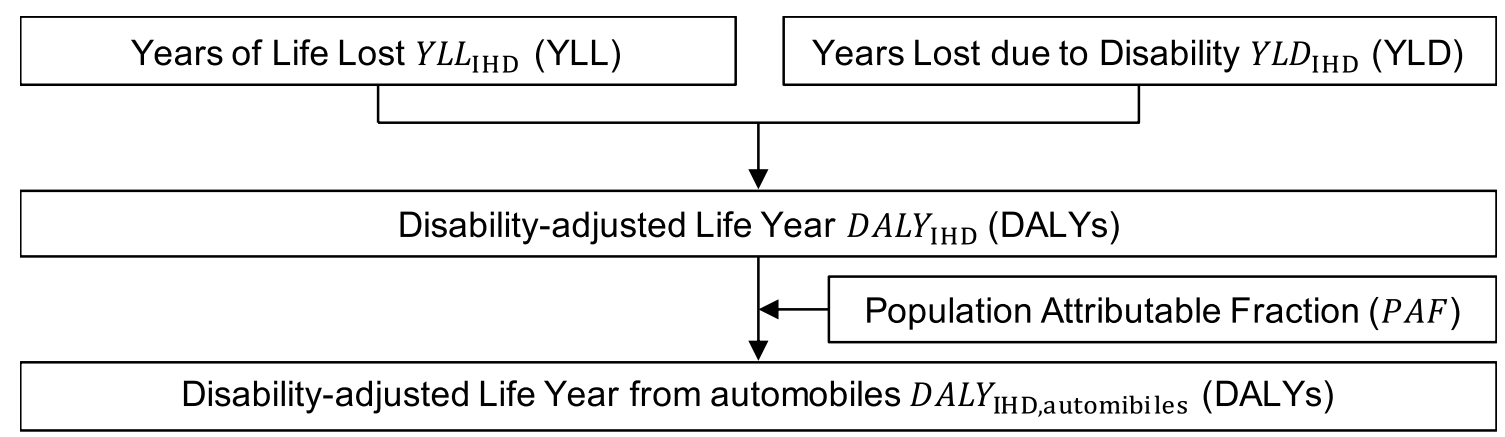

Fig. 4 Flowchart of health risk of ischemic heart disease estimation

$D A L Y_{\mathrm{IHD}, \text { automibiles }}=D A L Y_{\mathrm{IHD}} \cdot P A F$

where

DALY $_{\text {IHD,automobiles }}$ : Disability-adjusted Life Year from automobiles (DALYs).

DALY $_{\mathrm{IHD}}$ : Disability-adjusted Life Year (DALYs)

$D A L Y_{I H D}=Y L L_{I H D}+Y L D_{I H D}$

where

$Y L L_{I H D}$ : Years of Life Lost (YLL).

$Y L D_{I H D}$ : Years Lost due to Disability (YLD)

$P A F=\frac{\sum\left(P_{k} \cdot O R_{k}\right)-1}{\sum\left(P_{k} \cdot O R_{k}\right)}$

where

$P_{k}$ : Ratio of the exposed population in noise level band $k(-)$.

$O R_{k}$ : Odds ratio in noise level band $k(-)$.

$Y L L_{I H D}$ is the product of the number of deaths due to ischemic heart disease $N$ and life expectancy $L$ at each age (Eq. 11) (WHO/Europe 2011). The number of deaths due to ischemic heart disease at each age cohort is based on the number of deaths due to acute myocardial infarction and other ischemic heart disease in Osaka City (MHLW 2011). Life expectancy is based on the table of life expectancy by city, town, and village (MHLW 2013).

$Y L L_{I H D}=\sum\left(N_{j} \cdot L_{j}\right)$

where

$N_{j}$ : Number of deaths due to ischemic heart disease at age $j$ (person).

$L_{j}$ : Life expectancy at age $j$ (year).

$Y L D_{I H D}$ is obtained by multiplying the number of nonfatal patients with ischemic heart disease $I$ by the "disability weight" ( $D W$ ) (Eq. 12) (WHO/Europe 2011). $D W$ is a weighting factor reflecting the severity of the disease on the scale of 0 (perfect health) to 1 (equivalent to death) (WHO
2020). WHO/Europe (2011) substituted $D W$ for acute myocardial infarction because of the lack of data on $D W$ for ischemic heart disease. Similarly, the $D W$ for ischemic heart disease of 0.432 (Salomon et al. 2015) was used in this study. The number of non-fatal patients with ischemic heart disease is defined as the difference between total patients and deaths. As the data for Osaka City were unavailable, the data for total patients were derived from the total patients in Osaka Prefecture (MHLW 2012) by using the ratio of the population of Osaka Prefecture and Osaka City (Statistics Bureau of Japan 2014).

$Y L D_{I H D}=I \cdot D W$

where

$I$ : Number of non-fatal patients with ischemic heart disease (person).

$D W$ : Disability weight (-).

\subsubsection{Effects on high sleep disturbance}

The process of estimating the health risk of high sleep disturbance due to road traffic noise $D A L Y_{\mathrm{HSD} \text {,automobiles }}$ is shown in Fig. 5. The health risk of high sleep disturbance due to road traffic noise is calculated as the product of the population affected by high sleep disturbance in noise level band $k P O P_{H S D, k}$ and the $D W$ (Eq. 13) (WHO/Europe 2011). The Night Noise Guidelines for Europe (WHO/Europe 2009) suggested an average $D W$ of 0.07 for self-reported sleep disturbance, as presented below. Thus, the same value was used in this study.

$D A L Y_{\mathrm{HSD}, \text { automobiles }}=P O P_{H S D, k} \cdot D W$

where

$P O P_{H S D, k}$ : Population affected by high sleep disturbance in noise level band $k$ (person).

$D W$ : Disability weight (-).

The population affected by high sleep disturbance in noise level band $k P O P_{H S D, k}$ is calculated by multiplying 
Fig. 5 Flowchart of health risk estimation of high sleep disturbance

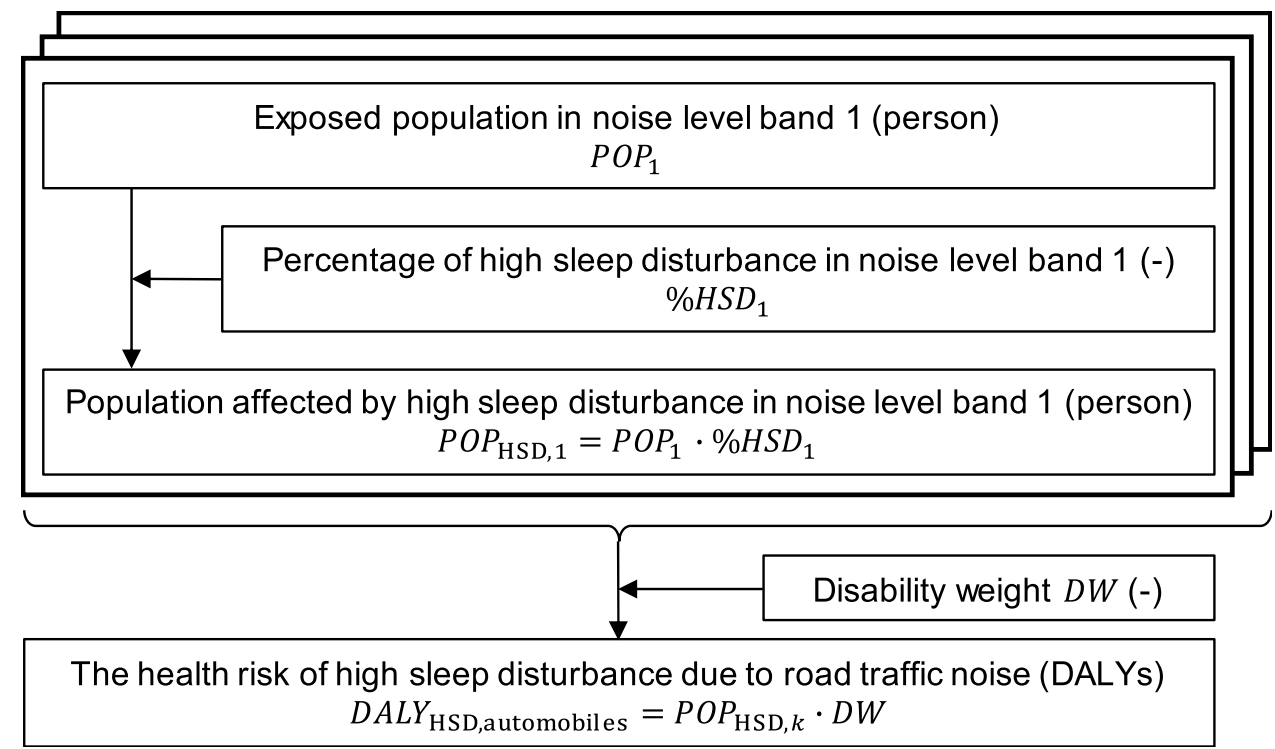

the percentage of the exposed population $P O P_{k}$ in noise level band $k$ by the percentage of high sleep disturbance (\%HSD) (Eq. 14). \%HSD represents the percentage of the exposed population affected by high sleep disturbance. Miedema et al. (2003) proposed a numerical relationship scheme between the percentage of the population affected by sleep disturbance and night-time A-weighted equivalent sound pressure level from "self-reported sleep disturbance." In epidemiological studies, "self-reported sleep disturbance" is the easiest measurement indicator of sleep disturbance (Miedema et al. 2003). Using "self-reported sleep disturbance," participants can relay the degree to which they are disturbed during sleep on a scale of 0 to 100 (Miedema et al. 2003). Miedema et al. (2003) summarized 15 datasets from 12 field studies using 50 and 72 as the cut-off values (i.e. in the order of "low sleep disturbance" (LSD), "sleep disturbance" (SD), and "high sleep disturbance" (HSD)) to identify the relationship between each condition and road traffic noise. By contrast, WHO/Europe (2011) identified only "high sleep disturbance" as an effect of road traffic noise. Determining whether "low sleep disturbance" and "sleep disturbance" are caused by road traffic noise is difficult. Therefore, in this study, only "high sleep disturbance" was adopted following the work of WHO/Europe. Equation 15 presents the relationship between $\% H S D$ and night-time A-weighted equivalent sound pressure level (Miedema et al. 2003). This equation is based on data with $45-65 \mathrm{~dB}$ range, but it can be extrapolated for lower levels $\left(L_{\text {night }}<45 \mathrm{~dB}\right)$ and higher levels ( $L_{\text {night }}>65 \mathrm{~dB}$ ) (Miedema et al. 2003). Given that Japan has environmental quality standards of $45 \mathrm{~dB}$ for night-time for residential areas (MOE 2012), the health risks at noise levels higher than $45 \mathrm{~dB}$ were estimated.
$P O P_{H S D, k}=P O P_{k} \cdot \% H S D_{k}$

where

$P O P_{k}$ : Exposed population in noise level band $k$ (person).

$\% H S D_{k}$ : Percentage of high sleep disturbance in noise level band $k(-)$

$\% H S D=20.8-1.05 \cdot L_{\text {night }}+0.01486 \cdot\left(L_{\text {night }}\right)^{2}$

where

$L_{\text {night }}:$ Night-time A-weighted equivalent sound pressure level $(\mathrm{dB})$.

\subsection{Estimation of health risks due to air pollutants from automobiles}

In this study, the health risks of air pollutants (nitrogen dioxide $\left(\mathrm{NO}_{2}\right)$ and $\left.\mathrm{PM}_{2.5}\right)$ from automobiles were estimated using the exposure, effect, and damage analytical methods (Itsubo and Inaba 2010) (Fig. 6). First, the lost DALYs per $1 \mu \mathrm{g} / \mathrm{m}^{3}$ of air pollutant were calculated from

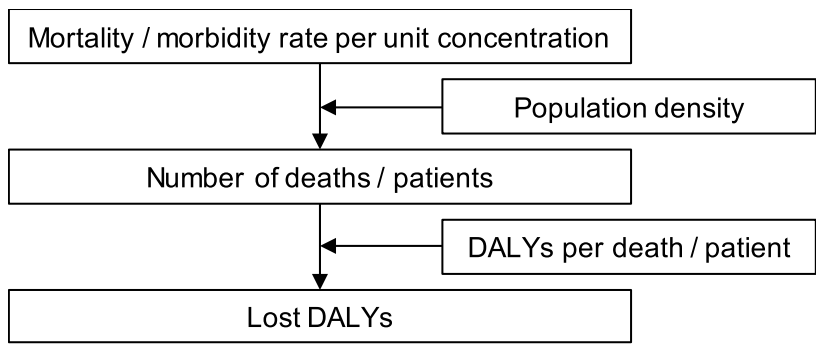

Fig. 6 Flowchart of health risk estimation per unit concentration of air pollutants 
the mortality and morbidity rates per $1 \mu \mathrm{g} / \mathrm{m}^{3}$ of air pollutant. The mortality rate per $1 \mu \mathrm{g} / \mathrm{m}^{3}$ of air pollutant was calculated by multiplying the increase in mortality rate per $1 \mu \mathrm{g} / \mathrm{m}^{3}$ of air pollutant (European Commission 1999) by the mortality rate in Japan. The mortality rate was calculated by dividing the number of deaths due to respiratory diseases (MHLW 2011) by the population of Japan (Statistics Bureau of Japan 2014). Then, the health risks in terms of DALYs were calculated using the observed concentrations of air pollutants. The respiratory diseases (acute death and respiratory hospitalization) (Itsubo and Inaba 2010) were adopted as the endpoint.

The difference between the median concentration of air pollutants observed at the ambient air pollution monitoring stations (Osaka Prefecture 2012) and the median concentration observed at the roadside air pollution monitoring stations (Osaka Prefecture 2012) is defined as the increase in air pollution emitted by automobiles. In Osaka City, the $\mathrm{NO}_{2}$ and $\mathrm{PM}_{2.5}$ concentrations were observed from 14 ambient air pollution monitoring stations and 11 roadside air pollution monitoring stations (Fig. 7). The ambient air pollution monitoring stations have been mainly set up to ascertain compliance with environmental quality standards and are not directly affected by specific sources. As for the roadside air pollution monitoring stations, they are located near the roadside where people live and work and where the influence of automobile emissions is most pronounced. Therefore, the difference in concentrations observed at

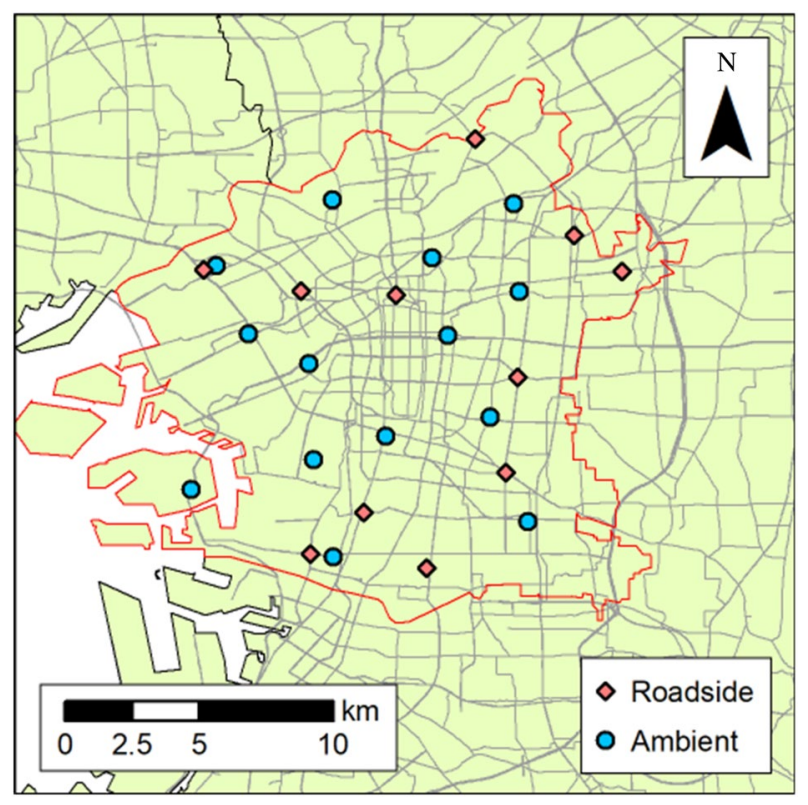

Fig. 7 Fourteen ambient air pollution monitoring stations and 11 roadside air pollution monitoring stations in Osaka City. Gray lines are the roads surveyed for the Road Traffic Census (JSTE 2012) these measuring stations can be considered an increase in concentration attributable to the automobiles.

\subsection{Sensitivity analysis of road traffic noise}

In this study, we considered the factors that could increase or decrease road traffic noise and conducted a sensitivity analysis. Considering the correlation between noise level and traffic volume (Eq. 4), the health risks due to road traffic noise were estimated when the traffic volume was varied. A total of 62,884,000 small-sized automobiles and $14,158,000$ large-sized automobiles, including trucks and buses, were forecasted to be owned in Japan in 2030, which were $107.8 \%$ and $92.8 \%$ of those in 2010 , respectively (Sougougiken 2019). For all automobile types, it was expected to be $104.6 \%$ of that in 2010 (Sougougiken 2019). Therefore, these values were used to assume an increase in traffic volume. When estimating the A-weighted equivalent sound pressure level for each automobile type in Eq. 4, the increase or decrease rate was multiplied by each automobile type.

As for the factors that could decrease the traffic volume, the spread of electric vehicles with high silent performance and the reduction in travel to prevent the spread of the current outbreak of the novel coronavirus (Velavan and Meyer 2020) were considered. The former exerts no major impact at present because the number of electric vehicles in Japan in 2020 was 119,159 (AIRIA 2021), which is less than 1\% of the total. With regard to the latter, using the year-on-year ratios of weekly traffic volume reported by MLIT (2021), we averaged the year-on-year ratios of major national highways in the area, including Osaka City, during the declaration of the state of emergency (April 7 to May 21 in 2020), and found that the year-on-year ratio was $93.7 \%$. Therefore, in this case, the change in health risk was estimated by multiplying by 0.937 for all automobile types as well as the case of increase.

\section{Results and discussions}

\subsection{Prediction of road traffic noise}

\subsubsection{Estimation of A-weighted equivalent sound pressure level}

In this study, the predictions of road traffic noise were taken into account from more than 700 sections. Then, the estimated values of these sections were compared with the observed values (NIES 2020) at 47 points. The estimated values were larger than the observed values at all points. Therefore, we calculated the error in which the sum of the squares of the differences between the estimated and observed values was the smallest. The corresponding values 
were $16.26 \mathrm{~dB}$ at daytime and $16.08 \mathrm{~dB}$ at night-time. Subsequently, $16.26 \mathrm{~dB}$ at daytime and $16.08 \mathrm{~dB}$ at night-time were subtracted from the estimated values to estimate the health risk. The comparison between the estimated and observed A-weighted equivalent sound pressure levels after calibration (NIES 2020) is shown in Fig. 8. On the basis of the calibration results, all of the estimated values at the 47 points were within the error margin of $\pm 20 \%$ of the observed values.

The distribution of calibrated A-weighted equivalent sound pressure levels is shown in Fig. 9. The vertical axis

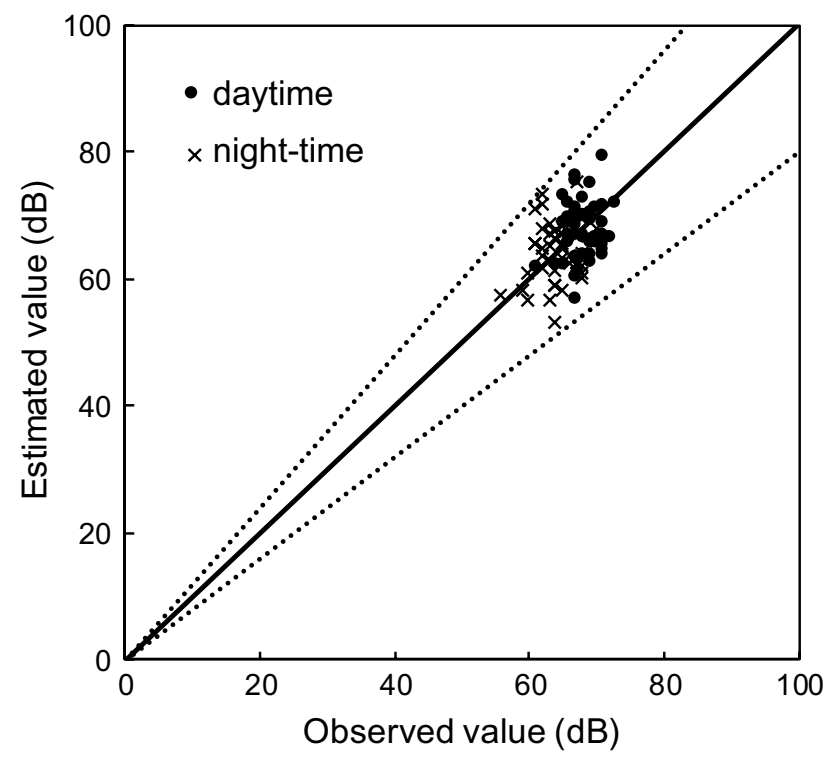

Fig. 8 Estimated and observed values of the A-weighted equivalent sound pressure level. Straight line means one-to-one correspondence; dotted line means $\pm 20 \%$ represents the sum of the percentage of the section in the whole targeted road. The total length of the targeted road was $414.9 \mathrm{~km}$. This finding corresponds to approximately $11 \%$ of the total length of the roads managed by Osaka City, which is 3,678 km (Osaka City 2020). With the open-window scenario, the percentage increased at daytime until the A-weighted equivalent sound pressure level reached $55 \mathrm{~dB}$, reaching a maximum of $39.2 \%$ in the $55-60 \mathrm{~dB}$ range, then the percentage decreased. By contrast, at night-time, the percentage increased until the A-weighted equivalent sound pressure level reached $50 \mathrm{~dB}$, reaching $38.4 \%$ in the $50-55 \mathrm{~dB}$ range and $34.7 \%$ in the $55-60 \mathrm{~dB}$ range, then the percentage decreased. With the closed-window scenario, the percentage of the A-weighted equivalent sound pressure level of $45 \mathrm{~dB}$ or less was the highest in both daytime and night-time, then the percentage decreased. The percentage was $67.5 \%$ at daytime and $94.0 \%$ at night-time. The results indicate that road traffic noise can be controlled below the environmental standard by closing windows.

\subsubsection{Estimation of exposed population}

The estimated exposed populations at daytime and nighttime (with windows opened/closed) are shown in Fig. 10. The exposed population was 822,000 at daytime and 534,000 at night-time. This higher population at daytime can be explained by the locations of many offices and schools in Osaka City. With the open-window scenario, the exposed population at daytime gradually increased from below $45 \mathrm{~dB}$ to the $55-60 \mathrm{~dB}$ range, reaching the largest population of 334,000 in the $55-60 \mathrm{~dB}$ range, then it decreased and reached 0 at $70 \mathrm{~dB}$. The exposed population at night-time gradually increased from below $45 \mathrm{~dB}$ and reached the peak of 207,000 in the $55-60 \mathrm{~dB}$ range, then it decreased to 0 in
Fig. 9 Percentages of length for each A-weighted equivalent sound pressure level. The road length for the same noise level band was totaled. The data with the closed-window scenario are represented using dots

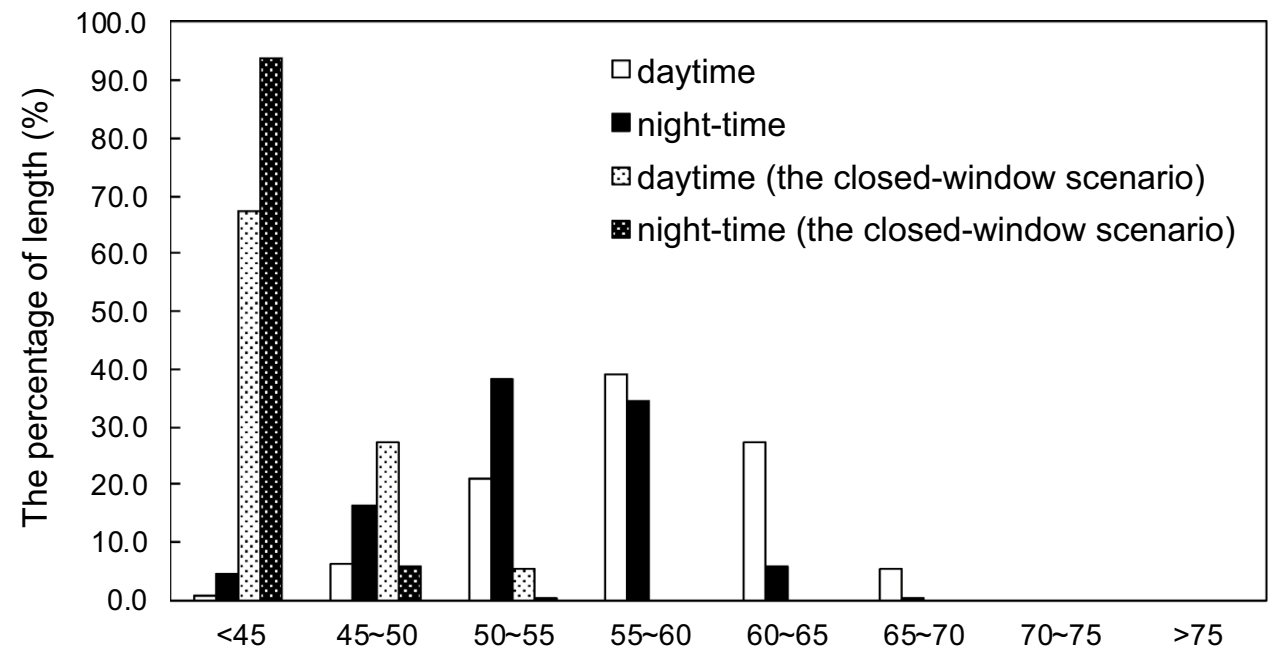

A-weighted equivalent sound pressure level (dB) 
Fig. 10 Exposed population by each equivalent sound pressure level. The data with the closedwindow scenario are represented using dots

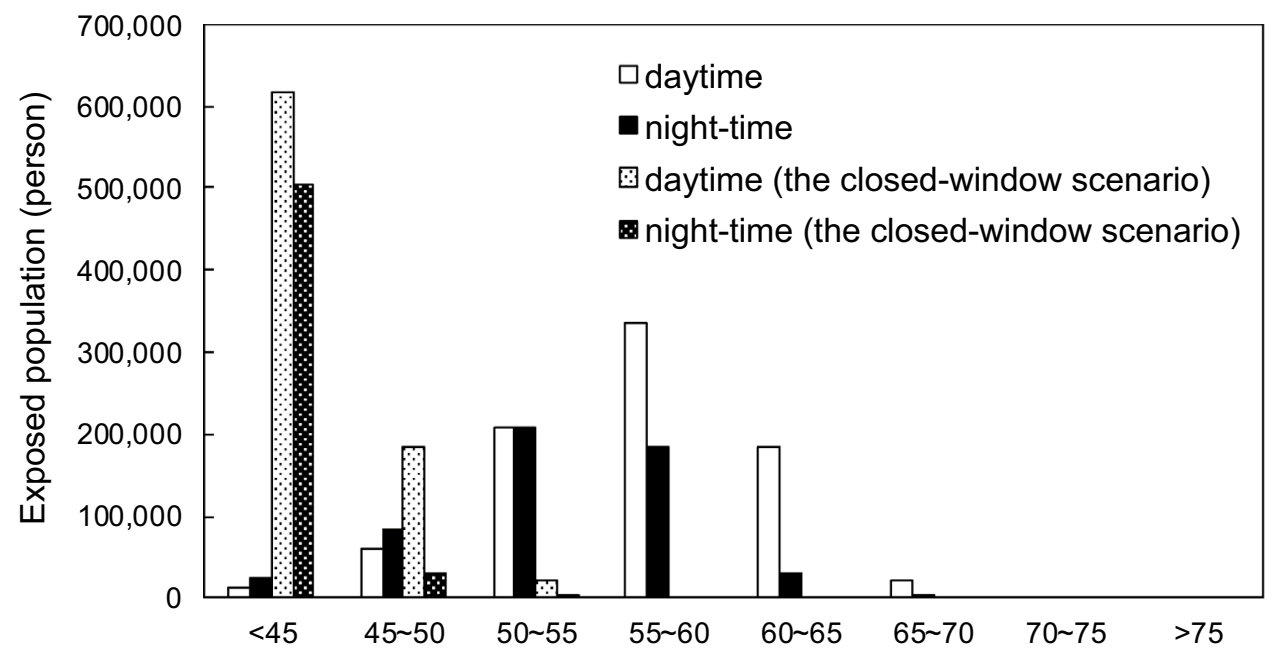

A-weighted equivalent sound pressure level $(\mathrm{dB})$ the $70 \mathrm{~dB}$. The exposed population at night-time was larger than the exposed population at daytime until $50 \mathrm{~dB}$, but the exposed population at daytime shifted to 5.9 times larger in the $60-65 \mathrm{~dB}$ range and more than 60 times larger in the $65-70 \mathrm{~dB}$ range. This trend may be related to the difference in traffic volume between daytime and night-time. According to the "Table of Traffic Volume by Time" of the Road Traffic Census (JSTE 2012), the average traffic volume in Osaka City for the same period was 609.2 automobiles/hour at daytime, whereas the volume was 203.5 automobiles/hour at night-time. As the A-weighted equivalent sound pressure level was determined by the traffic volume per unit time in Eq. 4, the decrease in traffic volume was considered to be the factor for the low number of exposed population at night-time. With the closed-window scenario, the exposed population in both daytime and night-time reached the peak of less than $45 \mathrm{~dB}$, and then decreased to more than $55 \mathrm{~dB}$ in both cases. The exposed population for the below $45 \mathrm{~dB}$ case was $75.1 \%$ of the total exposed population at daytime and $94.2 \%$ of the exposed population at night-time. The results are similar to those of the distribution of A-weighted equivalent sound pressure level.

\subsection{Estimation of health risks due to road traffic noise}

\subsubsection{Effects on ischemic heart disease}

Table 2 shows the results of the odds ratios for each noise level band calculated from the exposure-response relationship of Eq. 7. The $P A F$ for the open-window scenario was 0.010 after calculating Eq. 10. This value indicates that $1.0 \%$ of the deaths and patients with ischemic heart disease in Osaka City were caused by road traffic noise. WHO/Europe (2011) estimated a $P A F$ of 0.018 for the burden of disease from road traffic noise. Although the $P A F$ values in this study were below the WHO/Europe value, we considered the validity of the $P A F$ to be acceptable. Meanwhile, for the closed-window scenario, all of the exposed populations were exposed to below the environmental quality standards of $55 \mathrm{~dB}$. Therefore, the $P A F$ was calculated to be 0 in this study.

On the basis of the 1970 deaths from "acute myocardial infarction" and "other ischemic heart disease" (MHLW 2011) and the life expectancy (MHLW 2013) in Osaka City, the years of life lost due to ischemic heart disease $Y L L_{\mathrm{IHD}}$ was calculated to be 27,530.2 YLL. Meanwhile, as the total number of patients with ischemic heart disease in the Osaka Prefecture was reported to be 55,000 (MHLW 2012), the total number of patients with ischemic heart disease in Osaka City was estimated to be 16,535 . Subsequently, the number of non-fatal patients with ischemic heart disease
Table 2 Odds ratios by each equivalent sound pressure level

\begin{tabular}{lllllll}
\hline & \multicolumn{7}{l}{ Daytime equivalent sound pressure levels $(\mathrm{dB})$} \\
\cline { 2 - 7 } & $<55$ & $55 \sim 60$ & $60 \sim 65$ & $65 \sim 70$ & $70 \sim 75$ & $75 \sim 80$ \\
\hline Odds ratios (-) & 1.000 & 1.002 & 1.031 & 1.099 & 1.211 & 1.372 \\
\hline
\end{tabular}


in Osaka City was estimated to be 14,565 in this study; the number was derived by subtracting the number of deaths from the total number of patients. As the $D W$ of ischemic heart disease was assumed to be 0.432 (Salomon et al. 2015), the years lost due to disability $Y L D_{I H D}$ was 6,292.3 YLD. From the above discussions, $D A L Y_{I H D}$ was estimated to be $33,822.5$ DALYs for the sum of $Y L L_{I H D}$ and $Y L D_{I H D}$, and $P A F$ was 0.010 . Thus, the health risk of ischemic heart disease due to road traffic noise $D A L Y_{\text {IHD,automobiles }}$ was finally estimated to be 342.9 DALYs. Meanwhile, for the closedwindow scenario, the health risk of ischemic heart disease due to road traffic noise $D A L Y_{\text {IHD,automobiles }}$ was 0 .

\subsubsection{Effects on high sleep disturbance}

Figure 11 shows the exposed population and the population affected by high sleep disturbance for each noise level band. With the open-window scenario, the affected population increased as the exposed population increased, reaching the peak of 17,746 in the $55-60 \mathrm{~dB}$ range. The population exposed to $60-65 \mathrm{~dB}$ was reduced to approximately onesixth of the population exposed to 55-60 dB, but the affected population was reduced to only one-fourth. These findings can be explained by the high noise levels that were more sensitive to high sleep disturbance. Using Eq. 13, the health risk was estimated by multiplying the affected population by the $D W$ of 0.07 (WHO/Europe 2009), which was estimated to be 2,755.2 DALYs. With the closed-window scenario, the maximum number of people exposed to $45 \mathrm{~dB}$ or less, which was excluded from the effects of night-time noise, was approximately 500,000 . The affected population was only 1377 in the $45-50 \mathrm{~dB}$ range and 21 in the $50-55 \mathrm{~dB}$ range. Similar to the case of opened windows, the health risk was estimated to be 97.8 DALYs. Thus, closed windows can reduce the health risk to $3.5 \%$ of the risk with respect to the case of opened windows.
Fig. 11 a Population exposed to night-time road traffic noise and population with high sleep disturbance. b Exposed population and affected population in the case of closed windows. The numbers in the graph represent the ratio of affected population to exposed population
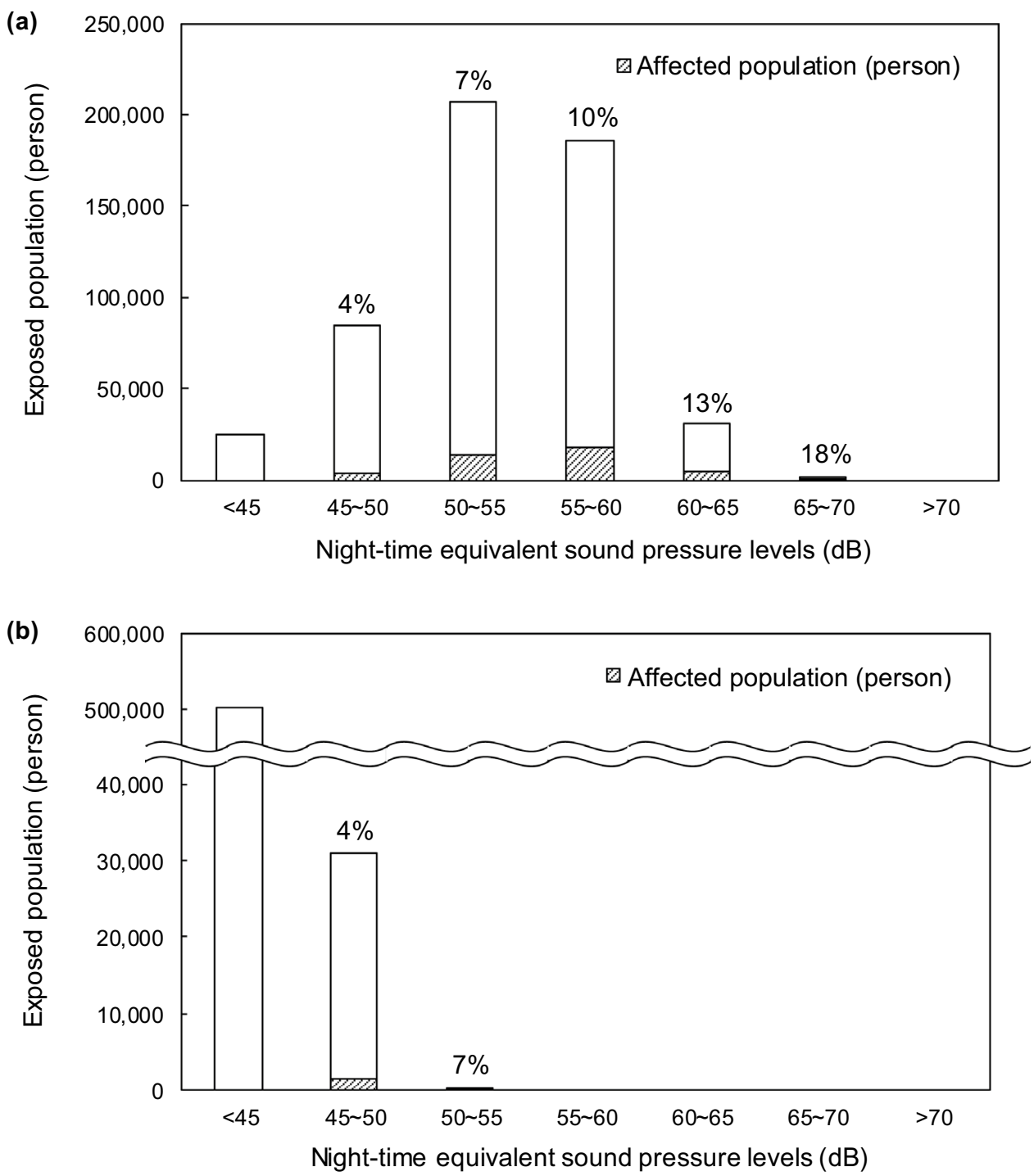
Table 3 Health risks due to air pollutants $\left(\mathrm{NO}_{2}\right.$ and $\left.\mathrm{PM}_{2.5}\right)$ caused by automobiles

\begin{tabular}{llc}
\hline & \multicolumn{2}{l}{ Respiratory disease (DALYs) } \\
\cline { 2 - 3 } & Acute death & Hospitalization \\
\hline $\mathrm{NO}_{2}$ & 2.4 & 99.5 \\
$\mathrm{PM}_{2.5}$ & 0.7 & 35.0 \\
Total & 3.1 & 134.5 \\
\hline
\end{tabular}

\subsection{Estimation of health risks due to air pollutants from automobiles}

Table 3 shows the health risks of air pollutants from automobiles. The health risk per unit concentration shown in Fig. 6 is $4.48 \times 10^{-9}$ DALYs $/\left(\mu \mathrm{g} / \mathrm{m}^{3}\right)$ for acute death and $1.85 \times 10^{-7} \mathrm{DALY} s /\left(\mu \mathrm{g} / \mathrm{m}^{3}\right)$ for respiratory hospitalization due to $\mathrm{NO}_{2}$, while the values are $8.95 \times 10^{-9}$ DALYs/ $\left(\mu \mathrm{g} / \mathrm{m}^{3}\right)$ for acute death and $4.56 \times 10^{-7} \mathrm{DALYs} /\left(\mu \mathrm{g} / \mathrm{m}^{3}\right)$ for respiratory hospitalization due to $\mathrm{PM}_{2.5}$. The health risk per unit concentration for respiratory hospitalization was 41.2 and 50.9 times greater than the health risk per unit concentration for acute death for each air pollutant. Thus, the effect on respiratory hospitalization was greater than that on acute death. Moreover, one acute death and one respiratory hospitalization would lose 0.75 DALYs and 0.011 DALYs, respectively. Although the value for acute death was larger than the value for respiratory hospitalization, the final health risk per unit concentration was estimated to be greater for respiratory hospitalization because of the smaller mortality rate from respiratory diseases in Japan. The total health risk, including concentration and population, was estimated to be 3.1 DALYs for acute death and 134.5 DALYs for respiratory hospitalization, totaling 137.6 DALYs. The health risk per unit concentration was greater for $\mathrm{PM}_{2.5}$ than for $\mathrm{NO}_{2}$, but the trend for the total health risk was the opposite. The difference can be attributed to the difference in $\mathrm{PM}_{2.5}$ concentrations observed at the roadside air pollution monitoring stations, and the ambient air pollution monitoring station was smaller than the difference in $\mathrm{NO}_{2}$ concentrations.

\subsection{Comparison of health risks and countermeasures}

The health risks estimated in this study is shown in Fig. 12 . The health risks due to road traffic noise were estimated to be 3,102.1 DALYs with the opened windows and 97.8 DALYs with the closed windows. The health risks were reduced to $3.2 \%$ with the closed windows. Meanwhile, the health risks of air pollutants from automobile was 137.6 DALYs, which were higher than the health risks of road traffic noise in the closed-window case. The health risks of air pollutants from automobile were estimated using the observed values obtained in outdoor stations and should be compared with the health risks due to road traffic noise with windows open. In this case, the health risks due to road traffic noise was 22.5 times greater than that due to air pollutants from automobile.

This study has shown the benefits of closing windows. By closing windows, all of the exposed population can stay below the environmental quality standards of $55 \mathrm{~dB}$ exposure at daytime. Moreover, this study found that the health risk can be reduced by $96.5 \%$ at night-time. Furthermore, closing windows is expected to reduce the health risks due to air pollutants from automobile. Therefore, closing windows is an effective countermeasure against the challenges posed by automobiles. As for the $55-60 \mathrm{~dB}$ range, this study found that the highest percentage of the exposed
Fig. 12 Comparison of health risks between road traffic noise and air pollutants derived from automobiles. Numbers in the graph indicate the health risk for each disease. The health risks caused by $\mathrm{NO}_{2}$ and $\mathrm{PM}_{2.5}$ are integrated into the health risks of "air pollutants"

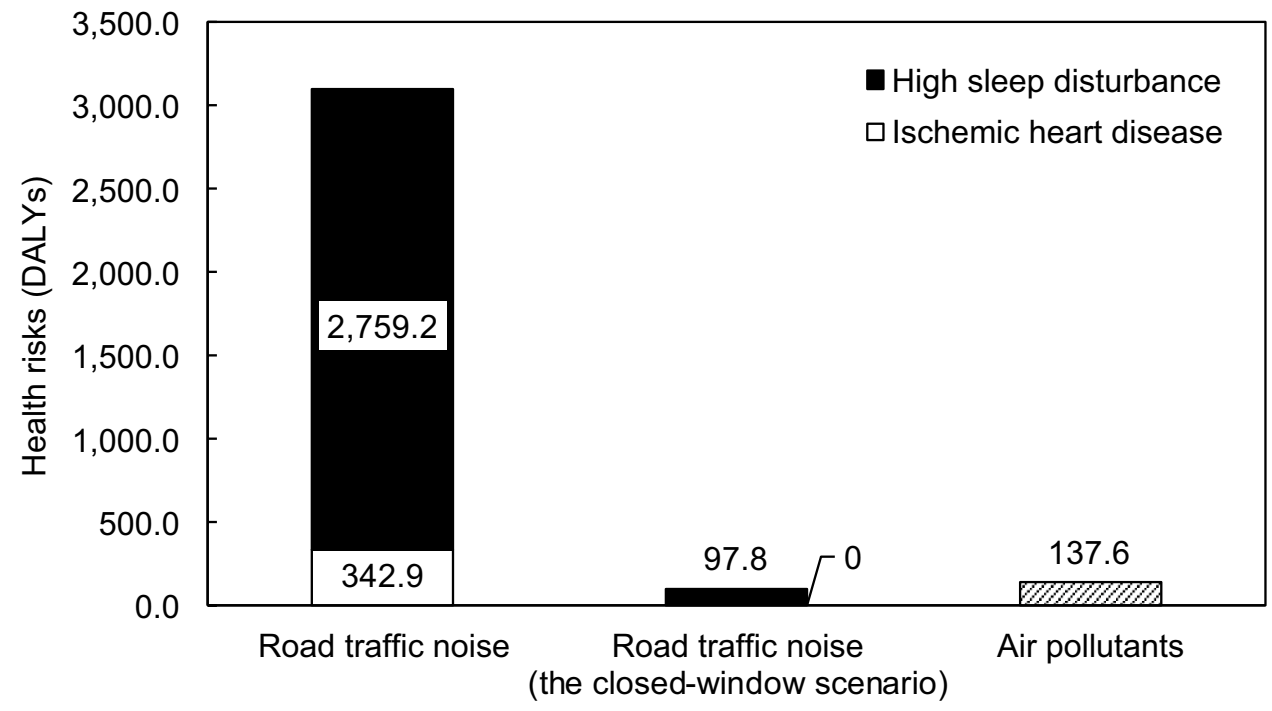


population had been for the open-window case, and the percentage of people who feel extremely uncomfortable with road traffic noise is only approximately $10 \%$ (Miedema and Oudshoorn 2001; Kuno 1998). Furthermore, people would become accustomed to repeated exposure to noise (Basner et al. 2011). However, the risk of ischemic heart disease increases at exposures beginning $55 \mathrm{~dB}$ (Babisch 2008). The environmental quality standards have been set as $55 \mathrm{~dB}$ at daytime for residential areas (MOE 2012), the risk of high sleep disturbance increases starting from $45 \mathrm{~dB}$ (Miedema et al. 2003), and the environmental quality standards are set as $45 \mathrm{~dB}$ at night-time for residential areas (MOE 2012). Thus, health risks are likely to occur even at the noise levels of 55-60 dB in cases in which people do not normally perceive these $\mathrm{dB}$ ranges as noise. The highest percentage of the population was unconsciously exposed to noise for a long time when their windows were opened, and they might have been at risk of eventual health problems.

\subsection{Sensitivity analysis of road traffic noise}

The results of sensitivity analysis in this study are shown in Table 4. The numbers in parentheses are the percentage changes compared with usual. In the forecast of increased traffic volume in 2030, the health risk of ischemic heart disease was 348.1 DALYs with the open-window scenario, an $1.5 \%$ increase than usual. With the closed-window scenario, it was 0 DALYs, the same as usual. Conversely, the health risk of high sleep disturbance increased by $0.8 \%$ to 2780.6 DALYs with the open-window scenario compared with usual but decreased by $4.2 \%$ to 93.8 DALYs with the closed-window scenario. This result is thought to be due to the decrease in the number of large-sized automobiles with large values of constant $a$ given for each automobile type in Table 1.

When the traffic volume was decreased during the declaration of the state of emergency, the health risk of ischemic

Table 4 Results of sensitivity analysis

\begin{tabular}{lll}
\hline Increase in traffic volume & $\begin{array}{l}\text { Ischemic heart } \\
\text { disease (DALYs) }\end{array}$ & $\begin{array}{l}\text { High sleep distur- } \\
\text { bance (DALYs) }\end{array}$ \\
\hline $\begin{array}{l}\text { With open-window } \\
\text { scenario }\end{array}$ & $348.1(101.5 \%)$ & $2780.6(100.8 \%)$ \\
$\begin{array}{l}\text { With closed-window } \\
\text { scenario }\end{array}$ & $0(-)$ & $93.8(95.8 \%)$ \\
\hline $\begin{array}{l}\text { Decrease in traffic volume } \\
\text { Ischemic heart } \\
\text { disease (DALYs) }\end{array}$ & $\begin{array}{l}\text { High sleep distur- } \\
\text { bance (DALYs) }\end{array}$ \\
\hline $\begin{array}{l}\text { With open-window } \\
\text { scenario }\end{array}$ & $313.0(91.3 \%)$ & $2699.3(97.8 \%)$ \\
$\begin{array}{l}\text { With closed-window } \\
\text { scenario }\end{array}$ & $0(-)$ & $87.7(89.6 \%)$ \\
\hline
\end{tabular}

heart disease decreased by $8.7 \%$ to 313.0 DALYs with the open-window scenario. With the closed-window scenario, it was 0 DALYs, the same as usual. Meanwhile, the health risk of high sleep disturbance was 2699.3 DALYs with the open-window scenario and 87.7 DALYs with the closedwindow scenario, a decrease of $2.2 \%$ and $10.4 \%$, respectively. Decreasing traffic to prevent the spread of the novel coronavirus reduced the health risk of high sleep disturbance by more than $10 \%$ with closed windows, suggesting that reducing traffic is effective in controlling health effects.

\section{Conclusions}

In this study, we successfully estimated the health risks due to road traffic noise using DALYs as a common indicator, and compared it with those due to air pollutants from automobiles.

The health risks due to road traffic noise were estimated and compared with those due to air pollutants from automobiles in Osaka City. As road traffic noise level varies with the sound performance of buildings, the health risks were estimated using two scenarios, namely, (1) opened windows and (2) closed windows. The number of people exposed to the daytime A-weighted equivalent sound pressure level was 822,000 , whereas the number of people exposed to night-time A-weighted equivalent sound pressure level was 534,000. The larger population at daytime than that at night-time can be explained by the many offices and schools located in Osaka City. With opened windows, the largest exposed population was 334,000 at daytime (55-60 dB), whereas the largest exposed population was 207,000 at night-time (55-60 dB). With closed windows, the exposed population was largest at less than $45 \mathrm{~dB}$ exposure at both daytime and night-time. The risk of ischemic heart disease was 342.9 DALYs for the openwindow scenario and 0 DALYs for the closed-window case. The difference can be attributed to all of the exposed population that was below the daytime environmental quality standards of $55 \mathrm{~dB}$. The risk of high sleep disturbance was 2755.2 DALYs with opened windows and 97.8 DALYs with closed windows. The closed windows had reduced the health risk by $96.5 \%$.

The health risk due to air pollutants from automobiles was 3.1 DALYs for acute death and 134.5 DALYs for respiratory hospitalization. The total health risks due to road traffic noise were 3102.1 DALYs with the open-window scenario and 97.8 DALYs with the closed-window scenario. The health risk due to air pollutants from automobiles was estimated using the observed values obtained from the roadside air pollution monitoring stations, which were better for comparison with the health risks due to road traffic noise for the open-window scenario. In this 
case, the health risk due to road traffic noise was 22.5 times larger than those due to air pollutants from automobiles. This study has shown that closing windows contributes to the reduction of health risks due to road traffic noise. However, in the 55-60 dB range in which the population was most likely exposed because of their opened windows, only approximately $10 \%$ of the population felt extremely uncomfortable with road traffic noise, further suggesting that those people might be living with their windows open. In addition, people accustomed to noise through long-term exposure in the open-window case might have been unconsciously exposed to noise level bands that pose risks of ischemic heart disease and high sleep disturbance.

Acknowledgements This study was supported by the Study on Sound Management of Chemicals with Relevant Legal Framework (METI) in FY 2020.

\section{References}

Automobile Inspection \& Registration Information Association (AIRIA) (2020) "Changes in the Number of Automobiles Owned" [Translated from Japanese.] https://www.airia.or.jp/publish/stati stics/ub83el00000000wo-att/hoyuudaisuusuii02.pdf. Accessed 23 October 2020

Automobile Inspection \& Registration Information Association (AIRIA) (2021) "Changes in the Number of Electric Vehicle and Hybrid Vehicle Owned" [Translated from Japanese.] https://www. airia.or.jp/publish/file/r5c6pv000000u7b6-att/04_HV_EV.pdf. Accessed 23 January 2021

Babisch W (2008) Road traffic noise and cardiovascular risk. Noise Health 10:27-33. https://doi.org/10.4103/1463-1741.39005

Babisch W (2011) Cardiovascular effects of noise. Noise Health 13(52):201-204. https://doi.org/10.4103/1463-1741.80148

Basner M, Muller U, Elmenhorst EM (2011) Single and combined effects of air, road, and rail traffic noise on sleep and recuperation. Sleep 34(1):11-23. https://doi.org/10.1093/sleep/34.1.11

Eriksson C, Bodin T, Selander J (2017) Burden of disease from road traffic and railway noise - a quantification of healthy life years lost in Sweden. Scand J Work Environ Health 43(6):519-525. https:// doi.org/10.5271/sjweh.3653

Fenger J (1999) Urban air quality. Atmos Environ 33(29):4877-4900. https://doi.org/10.1016/S1352-2310(99)00290-3

Fukazawa K, Tagusari J, Matsui T (2016) "Methodological Study for Estimating Population Exposed to Road Traffic Noise Based on Noise Map" [Translated from Japanese.] Proceedings of the autumn meeting, the institute of Noise Control Engineering of Japan :219-222

GBD 2017 DALYs and HALE Collaborators (2018) Global, regional, and national disability-adjusted life-years (DALYs) for 359 diseases and injuries and healthy life expectancy (HALE) for 195 countries and territories, 1990-2017: a systematic analysis for the Global Burden of Disease Study 2017. Lancet 392(10159):18591922. https://doi.org/10.1016/S0140-6736(18)32335-3

Institute of Noise Control Engineering of Japan (INCE/J) (2019) Guide to noise regulation. Gihodo Shuppan

Itsubo N, Inaba A (2010) LIME 2: Life-cycle impact assessment method based on endpoint modeling. Maruzen Publishing
Japan Society of Traffic Engineers (JSTE) (2012) FY 2010 road traffic census. Maruzen Publishing

Kuno K (1998) "Physiological and Psychological Effects of Road Traffic Noise"[Translated from Japanese]. The Journal of the INCE of Japan 22(6):317-321. https://doi.org/10.11372/souonseigyo1977 .22 .317

Miedema HME, Oudshoorn CGM (2001) Annoyance from Transportation Noise: Relationships with Exposure Metrics DNL and DENL and Their Confidence Intervals. Environ Health Perspect 109(4):409-416. https://doi.org/10.1289/ehp.01109409

Miedema HME, Passchier-Vermeer W, Vos H (2003) Elements for a position paper on night-time transportation noise and sleep disturbance. TNO Inro report 2002-59

Ministry of Health, Labour and Welfare (MHLW) (2000) "Health Japan 21" [Translated from Japanese.] https://www.mhlw.go.jp/www1/ topics/kenko21_11/top.html. Accessed 23 January 2020

Ministry of Health, Labour and Welfare (MHLW) (2011) Vital Statistics. "Number of Deaths, Months of Death, Sex, Age, and Cause of Death by Prefecture" [Translated from Japanese.] https://www.e-stat.go.jp/stat-search/files?page=1\&layout=datal ist $\&$ touke $i=00450011 \&$ kikan $=00450 \&$ tstat $=0000010288$ $97 \&$ cycle $=7 \&$ year $=20100 \&$ month $=0 \&$ tclass $1=0000010530$ $58 \&$ tclass $2=000001053061 \&$ tclass $3=000001053074 \&$ tclas s4 $=000001053089 \&$ stat_infid $=000011818452 \&$ result_back $=1$. Accessed 23 October 2020

Ministry of Health, Labour and Welfare (MHLW) (2012) Patient Survey. "Total Patients by Sex and Age, by Disease, and by Prefecture" [Translated from Japanese.] https://www.e-stat.go.jp/statsearch/files?page $=1 \&$ layout $=$ datalist $\&$ toukei $=00450022 \&$ bunya $\_1=15 \&$ tstat $=000001031167 \&$ cycle $=7 \&$ tclass $1=0000010558$ $80 \&$ tclass $2=000001055883 \&$ stat_infid $=000017031130$. Accessed 23 October 2020

Ministry of Health, Labour and Welfare (MHLW) (2013) Life Tables. "FY 2010 Life Tables by Municipality" [Translated from Japanese.] https://www.e-stat.go.jp/stat-search/files?page=1\&layou $\mathrm{t}=$ datalist \& toukei $=00450012 \&$ kikan $=00450 \& \mathrm{tstat}=0000010313$ $36 \&$ cycle $=7 \&$ tclass $1=000001060926 \&$ tclass $2=0000010612$ 60\&stat_infid $=000021664342$. Accessed 23 October 2020

Ministry of Internal Affairs and Communications (MIC) (2019) "FY 2018 Survey of Complaints Against Pollution" [Translated from Japanese.] https://www.soumu.go.jp/main_content/000681118. pdf. Accessed 23 October 2020

Ministry of Land, Infrastructure, Transport and Tourism (MLIT) (2019a) Survey on Motor Vehicle Transport. "Ton-kilometers by Industry and by Vehicle Type in Six Major Prefectures" [Translated from Japanese.] https://www.e-stat.go.jp/stat-search/files ?page $=1 \&$ layout $=$ datalist \&toukei $=00600330 \&$ bunya $\_1=10 \&$ tstat $=000001078083 \&$ cycle $=8 \&$ year $=20181 \&$ month $=0 \&$ stat_infid $=000031852432 \&$ result_back $=1 \&$ result_page $=1 \&$ tclass 1 val $=0$. Accessed 23 October 2020

Ministry of Land, Infrastructure, Transport and Tourism (MLIT) (2019b) Survey on Motor Vehicle Transport. "Person-kilometers by Vehicle Type in Six Major Prefectures" [Translated from Japanese.] https://www.e-stat.go.jp/stat-search/files?page=1\&layou $\mathrm{t}=$ datalist\&toukei $=00600330 \&$ bunya_l $=10 \& \mathrm{tstat}=0000010780$ $83 \&$ cycle $=8 \&$ year $=20181 \&$ month $=0 \&$ stat_infid $=0000318524$ $41 \&$ result_back $=1 \&$ result_page $=1 \&$ tclass 1 val $=0$. Accessed 23 October 2020

Ministry of Land, Infrastructure, Transport and Tourism (MLIT) (2021) "Changes in Traffic Volume on Major Sections of Expressways and Major National Highways in Major Urban Areas in Japan" [Translated from Japanese] https://www.mlit.go.jp/road/ road_fr4_000090.html. Accessed 23 January 2021

Ministry of the Environment (MOE) (2012) Environmental Quality Standards for Noise. https://www.env.go.jp/en/air/noise/noise .html. Accessed 23 October 2020 
Ministry of the Environment (MOE) (2015a) "Manual for Automobile Noise Monitoring" [Translated from Japanese.] https://www.env. go.jp/air/car/noise/note/kanshimanual.pdf. Accessed 23 October 2020

Ministry of the Environment (MOE) (2015b) "Manual for Evaluation of Environmental Quality Standards for Noise: Roadside Areas" [Translated from Japanese.] https://www.env.go.jp/air/noise/ manual/02_douromensuru_manual.pdf. Accessed 23 October 2020

Murray CJL. Lopez AD (1996) The Global Burden of Disease. Harvard School of Public Health

National Institute for Environmental Studies (NIES) (2020) Environmental GIS. "Status Report of Motor Vehicle Traffic Noise" [Translated from Japanese.] https://tenbou.nies.go.jp/gis/monit or/?map_mode $=$ monitoring_map\&field=8. Accessed 23 October 2020

Osaka City (2020) "Current State of the Roads in Osaka City" [Translated from Japanese.] https://www.city.osaka.lg.jp/kensetsu/ page/0000372123.html\#: :text=\%E5\%A4\%A7\%E9\%98\%AA\% E5\%B8\%82\%E5\%86\%85\%E3\%81\%AE\%E9\%81\%93\%E8\%B7\% AF,\%E7\%A8\%AE\%E9\%A1\%9E\% $3 \% 81 \%$ AB\%E5\%88\%86\%Е $3 \% 81 \% 8 \mathrm{~B} \% \mathrm{E} 3 \% 82 \% 8 \mathrm{C} \% \mathrm{E} 3 \% 81 \% \mathrm{~A} 6 \% \mathrm{E} 3 \% 81 \% 84 \% \mathrm{E} 3 \% 81 \% \mathrm{~B}$ E\%E3\%81\%99\%E3\%80\%82. Accessed 23 October 2020

Osaka Prefecture (2012) "FY 2011 Results of Air Pollution Monitoring" [Translated from Japanese.] http://taiki.kankyo.pref.osaka.jp/ taikikanshi/taiki_sokutei/h23/index.html. Accessed 23 October 2020

Sakamoto S (2014) ASJ prediction model 2013 for road traffic noise: report from the research committee on road traffic noise in the acoustical society of japan translated from japanese. J Acoustic Society Japan 70(4):172-230. https://doi.org/10.20697/ jasj.70.4_172

Salomon JA, Haagsma JA, Davis A, de Noordhout CM, Polinder S, Havelaar AH, Devleesschauwer B, Kretzschmar M, Speybroeck N, Murray CJL, Vos T (2015) Disability weights for the Global Burden of Disease 2013 study. Lancet Global Health 3(11):e712e723. https://doi.org/10.1016/S2214-109X(15)00069-8

Sougougiken (2019) Automotive Industry Forecast in 2030, 2019 Edition. Sougougiken

Statistics Bureau of Japan (2014) National Census. "Population by Sex, Area, Population Density, Sex Ratio, Percentage by Age, Ratio of Daytime Population to Night-time Population, Employed Persons 15 Years of Age and Over Based on Place of Usual Residence, Percent of Employed Persons 15 Years of Age and Over by Industry Based on Place of Working, Number of Private Households, Members per Private Household, Percent to Private Households, and Rate of Owned Houses" [Translated from Japanese.] https://www.e-stat.go.jp/stat-search/files?page=1\&layou $\mathrm{t}=$ datalist\&toukei $=00200521$ \&bunya $1=02 \& \mathrm{tstat}=0000010394$ $48 \&$ cycle $=0 \&$ tclass $1=000001065261 \&$ stat_infid $=0000255187$ 38. Accessed 23 October 2020

Statistics Bureau of Japan (2016) National Census. "Population, Changes in Population, Area, Population Density, Number of
Household, and Changes in the Number of Households" [Translated from Japanese.] https://www.e-stat.go.jp/stat-search/files ?page $=1 \&$ layout $=$ datalist $\&$ toukei $=00200521 \&$ bunya_l $=02 \&$ tstat $=000001080615 \&$ cycle $=0 \&$ tclas $s=000001089055 \&$ tclas s $2=000001089057 \&$ tclass $3=000001089086 \&$ stat infid $=00003$ $1472950 \&$ result_page $=1$. Accessed 23 October 2020

Sayers BMCA, Fliedner TM (1997) The critique of DALYs: a counterreply. Bull World Health Organ 75(4):383-384

Supreme Court of Japan (1995a) Judgements of the Supreme Court. Judgment concerning the case where the court determined that there was no illegality in the setting of the outdoor noise level for the car noise to which people living near an ordinary national road, etc. were exposed. https://www.courts.go.jp/app/hanrei_en/ detail $? \mathrm{id}=223$. Accessed 23 October 2020

Supreme Court of Japan (1995b) Judgements of the Supreme Court. Judgment concerning the case where people living near an ordinary national road and other roads claimed an injunction against the use of the roads by alleging that they suffered damage due to car noise, etc. from the roads, and the court determined that there was no illegality as a condition for granting an injunction. https ://www.courts.go.jp/app/hanrei_en/detail?id=224. Accessed 23 October 2020

Tagusari J, Takahashi H, Fukazawa K, Matsui T (2017) "Road Traffic Noise Map and Adverse Health Effects in Sapporo City" [Translated from Japanese] Proceedings of the autumn meeting, the institute of Noise Control Engineering of Japan :111-114

Tobias A, Recio A, Diaz J, Linares C (2015) Health impact assessment of traffic noise in Madrid (Spain). Environ Res 137:136-140. https ://doi.org/10.1016/j.envres.2014.12.011

Velavan TP, Meyer CG (2020) The COVID-19 epidemic. Trop Med Int Health 25(3):278-280. https://doi.org/10.1111/tmi.13383

van Gent HA, Rietveld P (1993) Road transport and the environment in Europe. Sci Total Environ 129:205-218. https://doi. org/10.1016/0048-9697(93)90171-2

World Health Organization (WHO) (2020) Disability Weights, Discounting and Age Weighting of DALYs. https://www.who.int/ healthinfo/global_burden_disease/daly_disability_weight/en/. Accessed 23 October 2020

World Health Organization Regional Office for Europe (WHO/Europe) (2009) Night Noise Guidelines for Europe. https://www.euro.who. int/_data/assets/pdf_file/0017/43316/E92845.pdf. Accessed 23 October 2020

World Health Organization Regional Office for Europe (WHO/ Europe) (2011) Burden of Disease from Environmental Noise. https://www.who.int/quantifying_ehimpacts/publications/e9488 8.pdf?ua $=1$. Accessed 23 October 2020

World Wide Fund for Nature (WWF) (2003) The Social Cost of Chemicals. https://wwfeu.awsassets.panda.org/downloads/1654reachc bafindoc.pdf. Accessed 23 January 2021

$\mathrm{Xu}$ B, Lin B (2015) Factors affecting carbon dioxide $\left(\mathrm{CO}_{2}\right)$ emissions in China's transport sector: a dynamic nonparametric additive regression model. J Clean Prod 101:311-322. https://doi. org/10.1016/j.jclepro.2015.03.088 